\title{
Explorando las limitaciones del nuevo regionalismo en las políticas de la Unión Europea: Una perspectiva latinoamericana**
}

\begin{abstract}
From a Latin American's viewpoint -where the European Union (EU) is a reference point as a transnational integration-it is remarked at first the incapacity to revert regional asymmetries so as to build a Europe for all the regions as shown by dominant neoliberal and neoregionalist agendas involved in the EU's institutional building up. To explain that, we highlight the limitations of the regionalist perspective that had nurtured the EU's institutions and territorial policies that were both centrally founded in the belief that regions/localities were self-reproductive containers working in an unidirectional global local relationship, and in the inconsideration of asymmetric dynamics promoted from the neoliberal strategies at a national and supranational level. Trying to overcome those limitations and to formulate a strategy of alternate regional development, we stand out the need for inserting the regions in a more realistic and integrating macro-meso relationships, in which the role of the national State and the national paths and models are computed.
\end{abstract}

Key Words: New Regionalism; European Union; regional development

\section{Resumen}

Desde una mirada latinoamericana -donde la Unión Europea (UE) es tomada como referencia de integración transnacional- se remarca inicialmente la incapacidad de revertir las asimetrías regionales y construir una Europa para todas las regiones mostrada por las agendas neoliberal y neorregionalista dominantes en la construcción institucional de la UE. Para explicar ello, se destacan las limitaciones de la perspectiva regionalista que nutrió las instituciones y políticas territoriales en la UE, fundadas centralmente en la asunción de las regiones/localidades como containers autorreproductivos, que trabajan en una relación local global unidireccional y en la desconsideración de las dinámicas asimétricas promovidas desde las estrategias neoliberales en los niveles supranacionales y nacionales. Procurando superar esas limitaciones y formular una estrategia de desarrollo regional alternativa, destacamos la necesidad de insertar a las regiones en una relación macro-meso más realista e integradora, en la que se computa el papel del Estado nacional y las trayectorias/modelos nacionales.

Palabras clave: Unión Europea; Nuevo Regionalismo; desarrollo regional. 


\section{Introducción}

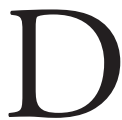

esde una mirada latinoamericana, este trabajo hace epicentro en el proceso de construcción institucional de la Unión Europea (UE) para analizar las potencialidades de las instituciones y políticas públicas inspiradas en el Nuevo Regionalismo (NR) y obtener un escenario de desarrollo integrador, donde la cohesión territorial y la convergencia avancen con una mejora en la competitividad de las regiones, localidades y empresas en las redes globales de producción e intercambio.

En trabajos previos destacamos cómo en el contexto del retroceso social, económico e institucional de América Latina (AL) durante los '90 - provocado por las estrategias neoliberales inspiradas en el Consenso de Washington (Stiglitz, 2003); (Portes; Hoffman, 2003) - el NR y las perspectivas localistas del desarrollo no pudieron superar el rol de identificadores -y exaltadores- de "islas exitosas de desarrollo local", incapaces de explicar y revertir el crecimiento de las asimetrías regionales (Fernández; Villalba, 2004).

Con tales antecedentes, nos centramos en la UE, intentando descubrir si en este laboratorio del reescalonamiento del capitalismo postfordista, el impulso del NR, combinado con una agenda neoliberal sobre la que fueron desarrollados los más importantes instrumentos institucionales del nivel supranacional, ofrece al contexto latinoamericano inputs teóricos y empíricos para detectar las limitaciones de los enfoques dominantes y repensar sus estrategias de desarrollo regional.

La decisión de colocar la experiencia europea en el centro de nuestro análisis, para relacionarla con la

* Magíster en Ciencias Sociales (FLACSO Buenos Aires). Doctor en Ciencias Políticas por la Universidad Autónoma de Madrid.

Investigador del CONICET y la Universidad Nacional del Litoral. Argentina. E-mail: rfernand@fcjs.unl.edu.ar

** El presente artículo fue desarrollado en el marco de una estadía como investigador visitante en el Departamento de Geografía de la Universidad de Durham (UK) y bajo la beca Arthur Prowse concedida por el Van Mildert College de la mencionada Universidad. El autor agradece la colaboración y comentarios de los Dres. Ash Amin; Gordon MacLeod y Ray Hudson del mencionado Departamento, aunque los mismos de ninguna manera son responsables por el contenido del presente trabajo. Enviado el 13 de septiembre de 2005, aprobado el 19 de octubre de 2006. latinoamericana, encuentra dos razones fundamentales:

- La primera surge de la posibilidad de evaluar el desarrollo combinado del NR y las estrategias neoliberales a nivel macro, en un contexto que, respecto del latinoamericano, además de ubicarse en una posición central en el sistema mundial, posee un sistema institucional fuerte y un históricamente más desarrollado stock de capital social y poder infraestructural del Estado.

- La segunda responde a que la estructuración institucional de la UE y sus políticas se presentaron como un exitoso modelo de inspiración para los procesos de unificación actualmente en AL.

Capitalizando esas razones, nos formulamos entonces los siguientes interrogantes: : pudo el matrimonio de los discursos y políticas neoliberales y neorregionalistas ser exitoso al enfrentar las asimetrías regionales de la UE? Este matrimonio teórico, ¿fue capaz de sentar las bases para una Europa de todas las regiones? Y descubrimos que, no obstante las dificultades de las instituciones europeas en admitirlo abiertamente, existe evidencia de que las asimetrías regionales y las dinámicas regionales no sólo no fueron revertidas, sino que, $y$ en varios sentidos, se incrementaron.

Considerando lo expuesto, la pregunta sería: ¡cuáles son los elementos o cuellos de botella que impidieron que la dinámica de desarrollo regional se expanda territorialmente, perpetuando y extendiendo las asimetrías regionales?

Tanto el mainstream académico como el staffde la UE persistieron en enfrentar estos interrogantes y buscar rutas alternativas insistiendo en el instrumental teórico del NR. Igualmente, el área académica vinculada a las instituciones europeas se mostró muy cuidadosa al sugerir la introducción de elementos externos-entendidos como políticas-a las diferentes regiones.

En este trabajo asumimos una postura y, de allí, una propuesta radicalmente diferente, ya que consideramos que la mayor parte del problema recae sobre las debilidades internas de la nueva perspectiva regionalista. Sostenemos que las políticas regionales de la UE han trabajado atadas a un cuerpo teórico 
que considera el desarrollo regional como una estrategia intramuros y que, paradójicamente en un contexto signado por una profunda globalización y procesos de integración supranacionales, concibe al territorio y a las regiones como cerramientos con capacidad para desarrollar estrategias autorreproductivas.

Discutimos esta postura afirmando que la perspectiva regionalista promueve una relación local-global que empobrece y mal interpreta las relaciones entre los procesos meso-regionales y la dinámica macroeconómica e institucional. Lo que es peor, pone a las estrategias de desarrollo regional a trabajar de una manera funcional y subordinada a las estrategias neoliberales y fuerzas sociales que no necesariamente apuntan al logro de una Europa social y territorialmente cohesionada. Creemos que las reformas y ajustes cualitativos que la UE promovió no podrán modificar las asimetrías estructurales entre las dinámicas de desarrollo macro y las dinámicas meso.

En consecuencia, afirmamos que es necesario un punto de vista alternativo para pensar e impulsar políticas de desarrollo regional en un proceso más complejo y multiescalar, que considere seriamente el rol y los efectos de la macroeconomía y las macroinstituciones al interpretar y definir estrategias de desarrollo meso-regional. Por ello, no sólo para detectar las asimetrías regionales, sino también para formular estrategias alternativas, remarcamos la necesidad de recuperar y considerar el rol estratégico que aún tienen en Europa los Estados y las trayectorias o modelos nacionales.

Este artículo posee tres partes. En la primera presentamos resumidamente cómo ocurrió la conjunta inserción institucional de la agenda neoliberal y de las estrategias regionalistas en el proceso de estructuración institucional de la UE. En la segunda parte examinamos los resultados que dichas estrategias tuvieron sobre la cohesión regional y la reducción de las asimetrías regionales y evaluamos las respuestas dadas por los niveles académicos e institucionales sobre los mismos. En la tercera, analizamos críticamente tales respuestas y sugerimos una explicación alternativa basada en las debilidades detectadas en los enfoques regionalistas. Finalmente, proponemos un marco de trabajo alternativo que incorpora la articulación de la dinámica regional con los procesos de desarrollo macro.

\section{Neoliberalismo y neorregionalismo en la estructuración institucional de la UE}

\subsection{La posición hegemónica del proyecto neoliberal en la UE}

Aunque el proceso de construcción institucional de la UE es anterior a las últimas grandes transformaciones del capitalismo postfordista, sin dudas éstas produjeron un cambio de rumbo significativo en el destino de la UE. Bajo estas transformaciones, la dinámica globalizadora impulsó a escala planetaria y en tiempo real una compleja red de flujos materiales e inmateriales, que paralelamente a un desconocido ensanchamiento espacial de las relaciones sociales (Rosenberg, 2000), promovieron un cambio radical en la lógica de "límites territoriales" dominantes dos décadas atrás (Amin, 2004). En ese contexto, fuerzas ascendentes y descendentes construyeron nuevas instancias de reproducción y conectividad locales y supranacionales que, interpenetrándose, contribuyeron a generar una profunda alteración en el papel de los espacios nacionales y del Estado nacional como referentes casi exclusivos de los procesos de reproducción económico-social (Brenner, 2003a; Swyngedouw, 2000).

Trabajando directamente sobre la conformación institucional de la UE, estas transformaciones dominadas por un fuerte y múltiple reescalonamiento espacial a nivel institucional y económico redefinieron el patrón de keynesianismo nacional sobre el cual estuvo basado el modelo de la UE en los '50. En este marco de redefiniciones tuvo lugar una fuerte lucha entre proyectos, ideas, instituciones y fuerzas sociales por la imposición de un perfil específico al "nuevo orden postfordista keynesiano" (Van Apeldoorn, 2003); (Young, 2000).

Debido a la complejidad de las políticas, actores e intereses nacionales, supranacionales y transnacionales involucrados (Cameron, 1995), y a la dinámica no lineal de los resultados de esos enfrentamientos, a fines de los'70 y principios de los '80 la integración de la UE mostraba avances mínimos. Pero desde mediados de los ' 80 y durante los ' 90 el proceso de integración política tomó un nuevo ritmo con el claro dominio de la agenda neoliberal (Williams, 1998). En los hechos, esta agenda representó un proyecto que promovido por fuerzas sociales e institucionales hegemonizadas por el capital financiero y las empre- 
sas transnacionales $(\mathrm{ET})$ - tomó primeramente una posición dominante en las instituciones supranacionales vinculadas al proceso de "reescalonamiento hacia arriba” (Gill, 1998).

En el campo de batalla entre actores, ideas e intereses, el proyecto neoliberal venció a dos estrategias de desarrollo alternativas. La primera expresaba un proyecto neomercantilista que pretendía implementar un dispositivo defensivo basado en la consolidación de un mercado europeo interno fuerte y el respaldo de los grandes complejos empresarios europeos, a los que se exaltaba, a la vez que se los desafiaba a actuar como "Los Campeones Europeos" (Pearce; Sutton, 1986). La segunda estrategia constituía un "proyecto socialdemócrata", basado en la defensa del "modelo social de la UE" y en la admisión de la apertura del mercado europeo (Van Apeldoorn, 2003; 1999).

La implementación del proyecto triunfante significó el establecimiento de una disciplina neoliberal que compelió a las instituciones nacionales y subnacionales a crear una estructura gubernamental amigable y segura para la expansión del capital global (Gill, 1998). Dos cuerpos institucionales reflejaron este objetivo estratégico en la UE. El primero fue la European Act (1986), y marcó el movimiento neoliberal más reconocido, dirigido al desmantelamiento del marco institucional keynesiano y del consenso neocorporativo de la posguerra (Young, 2000), por medio de un impresionante proceso de desregulación. Valiéndose del hiperoptimista y neoliberal Reporte Cechinni (Cechinni, 1988), la European Act llevó a los Estados nacionales europeos a dar curso a más de 300 medidas desregulatorias (Williams, 1998) que incrementaron considerablemente la libertad y movilidad del capital global en el proceso de unificación.

Pero, con conceptos de Peck y Tickell (2002), si los instrumentos de desmantelamiento contenidos en la European Union Single Act expresaron el movimiento de roll back del neoliberalismo, el segundo cuerpo institucional representado por el Tratado de Maastricht de 1993 -sobre el cual se construyó la Unión Monetaria Europea-indica el movimiento de roll out, encargado de promover nuevas instituciones regulatorias, capaces de coexistir en armonía con la integración regional y la hegemonía de las fuerzas globalizadoras. Desplazando el empleo subvencionado a través del gasto público como eje central de las políticas económicas (Dunford, 1995a; Gill, 1998), y emplazando como prioridad el control de la inflación (Delors Report, 1989), el Tratado de Maastricht atacó al corazón de las instituciones y políticas keynesianas, imponiendo compulsivamente un conjunto de reglas de convergencia. Ello significó una fuerte restricción supranacional para la política fiscal nacional -a través del control del déficit fiscal y de la deuda promedio/Producto Bruto Interno (PBI) - y una disminución de la autonomía de la política monetaria nacional al promover la conformación de una moneda única y un Banco Central Europeo "independiente" (Maastricht Treaty, 1991).

Con esos elementos, el proyecto neoliberal aseguró dos cuestiones al capital global: la reducción y contención -permanente- del poder político del Estado para establecer restricciones al mismo y el establecimiento de un entorno macroeconómico confiable para hacer negocios (Gill, 1998). Sin embargo, las instituciones de la UE presentaron los nuevos principios rectores como los cimientos de un mercado competitivo y para ofrecer la escala y transparencia necesaria para expandir el crecimiento y asegurar la prosperidad y convergencia para "todas" las regiones, naciones y emprendimientos (Delors, 1986; Dunford, 1995a).

Mientras este marco macroeconómico con su hegemónico imaginario se consolidaba durante los '90 y principios de 2000 -con la efectiva implementación de la moneda única, la creación del Banco Central Europeo y la firma de la Constitución Europea- desde mediados de los '90 la UE colocó y mantuvo a la competitividad en el centro de los debates políticos (EC, 1994; ERTI, 1993).

Capitalizando su significado difuso (Krugman, 1994), la competitividad fue blanco de diferentes metas. Primeramente, fue invocada en las metas más explícitas del proyecto neoliberal de reestructuración de los obstáculos a la libre competencia y a la explotación de las potencialidades de Europa (EC, 1997). Y con la estrategia de "neoliberalismo encastrado" (Ruggie, 1982), que trataba de incorporar parcialmente los proyectos derrotados -como el social demócrata-, el concepto de competitividad fue 
articulado con el interés por la cohesión social y territorial que, desde 1993, el Tratado de Maastricht puso como eje central de la UE.

Desde entonces, las políticas de la UE trataron de asociar la mejora en la competitividad con la cohesión territorial, usando como puente estratégico la noción de economía del aprendizaje, el conocimiento y la innovación. Ubicada en el centro -como verdadero sustento del crecimiento-la competitividad fue entendida como el resultado de la adaptación a la nueva economía del conocimiento, considerada por el Consejo Europeo de Lisboa (2000) como un objetivo estratégico en pos de un desarrollo sustentable. Pero la concreción de dicho objetivo, según las autoridades de la UE, requiere un mejoramiento de la cohesión social, expandiendo la educación y orientándola hacia la cualificación de las fuerzas de trabajo (EC, 2004:xii), y de la cohesión territorial, pues el crecimiento y la competitividad resultan inalcanzables globalmente si las regiones menos dinámicas no generan una dinámica innovativa capaz de contribuir a la competitividad global de la UE (EC, 2004:viii-xi).

Finalmente, la cohesión territorial y la reducción de las desigualdades territoriales dependen del desarrollo de mecanismos regionales y locales de aprendizaje e innovación que conduzcan a la competitividad (EC, 2004:xii).

\subsection{Surgimiento del NR bajo la hegemonía neoliberal}

Para enfrentar el desafío de construir un complementario escenario de competitividad y cohesión -social y territorial- bajo los puentes del conocimiento y la innovación, las políticas de la UE capitalizaron la nueva ola de regionalismo fortalecida en Europa desde los '80 (Keating, 1998) como resultado de las fuerzas descendentes de la reestructuración capitalista que presionan por una reducción del centralismo del Estado nacional y el surgimiento de relaciones locales-globales (Swyngedouw, 2000) y las limitaciones aplicadas al Estado nacional por las instituciones neoliberales desarrolladas desde el nivel supranacional de la UE (Dunford, 1995b).

Las raíces teóricas del NR que nutrieron la perspectiva territorial de la UE son conocidas (Amin, 1999; Mac Leod, 2001), pero es necesario recalcar que esta perspectiva es el resultado de un grupo de disciplinas y perfiles teóricos que desarrolló una masa crítica de conocimientos acerca del rol de las regiones como epicentros de desarrollo en la economía global (Omahe, 1996; Florida, 1995; Scott, Storper, 2003). El punto de convergencia de las diferentes contribuciones radica en la asociación estratégica entre los procesos de aglomeración y los de producción flexibles, lo que explica -según sus defensores- los numerosos casos exitosos que los modelos neoclásicos dominantes de la macroeconomía no pudieron visualizar y explicar (Scott, Storper, 2003).

Una plétora de conceptos, como capital social (Putnam et al., 1993), interdependencias no comerciales (Storper, 1995), economías asociacionales (Cooke, Morgan, 1998), ha sido introducida para explicar dentro de las regiones la relevancia adquirida por los activos relacionales. Sobre el desarrollo de éstos, el NR depositó la construcción de los patrones de organización colectivos basados en redes de actores públicos y privados que permiten reducir los costos de transacción y combinar flexibilidad con economías de escala (Scott, 1988) y, fundamentalmente, generar y difundir a nivel territorial los procesos de aprendizaje, generación de conocimiento e innovación demandados por el nuevo escenario globalizador.

Paralelamente, para establecer la conexión entre dicha perspectiva teórica y el proceso empírico regional-local que le da sustento, dentro del NR proliferaron conceptos claves para el análisis del desarrollo regional. A partir de la recuperación del concepto de distrito industrial, a principios de los ' 80 (Becattini, 1992), y de los aportes más recientes (Markusen, 1999); (Asheim, 2000), el NR incorporó nuevas categorías, entre las que se destacan las de medios de innovadores (Camagni, 1991) y regiones aprendientes (Florida, 1995). Sin embargo -principalmente desde la segunda mitad de los '90s-, los conceptos de cluster (CL) (Porter, 2000) y Sistemas Regionales de Innovación (SRI) (Cooke, 1998) adquirieron una presencia predominante en las instituciones y políticas de la UE. Esto se debe a la sensibilidad de dichos conceptos para remarcar la articulación entre los niveles territoriales y las redes de aprendizaje e innovación, transformadas en materia central de las estrategias de competitividad de la UE. 
Las políticas basadas en CL se convirtieron en una de las opciones principales para las políticas industriales y regionales en el contexto de la Organización para la Cooperación y el Desarrollo Económico (OECD) (Malmberg, Maskell, 2002), y para la estrategia formulada desde la UE hacia las pequeñas empresas (EC, 2002) e, incluso, dentro de la EU, para un nutrido y heterogéneo conjunto de programas nacionales de política industrial (Raines, 2001).

Además, el concepto de SRI inspiró un creciente número de programas, promovidos por las Comisiones Europeas de Política Regional y Política Industrial, que buscan articular el desarrollo regional e industrial con los procesos de innovación (Landabaso, 2000; Henderson, 2000). Como resultado de la propuesta del Consejo Europeo de transformar a la UE en la principal economía del conocimiento, la idea de redes territoriales de aprendizaje e innovación se convirtió en tema prioritario de las más recientes reformas de las políticas regionales promovidas por el Directorio General de Políticas Regionales, influyendo en la re-orientación de los Fondos Estructurales dirigidos a las regiones menos favorecidas (LFRs, less favoured regions) (EC, 2004:xi-xii). Ante las continuas reformas orientadas a simplificar y mejorar la coordinación de programas y aumentar los recursos invertidos (Rodríguez Pose; Fratesi, 2004), la tendencia fue desafiar a las LFRs (regiones de Objetivo 1) a abordar la competitividad regional y la convergencia con una combinación de estímulo al potencial de desarrollo endógeno, promoción del emprendedorismo y construcción de redes de instituciones científico técnicas y gubernamentales con Pequeñas y Medianas Empresas (PyMEs) (EC, 2004).

Destacable en esta estrategia fue el cambio en el rol de las regiones en el proceso de evolución de la UE. Éste puede observarse al contrastar la lógica y principios del Fondo de Desarrollo Regional Europeo (ERDF) de 1975 con los objetivos de las reformas de 1988, 1993 (Staeck, 1996) y 2004. De ser espacios con necesidad de ser ayudados y compensados por las políticas regionales de la UE con programas de asistencia (Petrella, 2000; Keating, 1998), las regiones se convirtieron en nodos de autoasistencia en competitividad y competencia interregional, encargados ahora de asistir y contribuir al desarrollo de la UE como un todo, en pos del cumplimiento y articulación de sus objetivos estratégicos de competitividad y cohesión.

Igualmente, para lograr esta estrategia de desarrollo socioeconómico, la perspectiva del NR estuvo presente en las crecientes iniciativas europeas supranacionales, nacionales y regionales que promueven la transferencia del poder de decisión hacia los niveles regionales, la cualificación del gobierno regional mediante la cooperación institucional y la implicación social a nivel territorial por medio de Agencias de Desarrollo Regional ADR (Amin, 2004; Batt, Wolczuk, 2002).

En síntesis, con la agenda macroeconómica neoliberal dominada por el interés del capital global e inserta en procesos de reescalonamiento hacia abajo (downscaling) operados por la re-estructuración capitalista, la perspectiva del NR fue estratégicamente incorporada a un nivel supranacional para atacar simultáneamente dos objetivos estratégicos: las exigencias de competitividad de la inserción global y el desarrollo territorial y socialmente asimétrico que preocupó a la UE desde su comienzo (Agnew, 2001).

\section{Evaluando la cohesión a partir de las estrategias del nuevo regionalismo en la UE}

\subsection{Expansión y persistencia de las asimetrías regionales en la UE a raíz del "matrimonio entre el neoliberalismo y el neorregionalismo"}

Probablemente, el interrogante más importante que deriva del análisis anterior es el siguiente: esta estrategia -que conjuga al NR con la hegemonía macroeconómica neoliberal- ¿hasta dónde fue capaz de alcanzar un proceso sustentable y coordinado de crecimiento, competitividad y cohesión en la UE?

Sin ser nuestro objetivo examinar la competitividad y el crecimiento, sólo destacamos que, considerando seriamente la percepción de la propia Comisión Europea (EC), la presencia de estas dos variables macro en el escenario europeo dista mucho de ser una realidad. El Tercer Reporte sobre la Cohesión Económica y Social-paradójicamente-afirma alarmantemente: “...el crecimiento económico se ha desacelerado considerablemente durante los tres años que pasaron desde la publicación del último Repor- 
te de Cohesión... y el funcionamiento de la economía de la UE en el largo plazo... sugiere que existen problemas más profundos que necesitan ser resueltos para que el crecimiento sea sostenible a tasas razonables en los años por venir..." (EC, 2004:vii). Por ende, la EC demanda de los Estados Regionales y Nacionales un compromiso con el mejoramiento de la competitividad a través del desarrollo de conocimiento y de procesos de innovación; pero también reconoce las debilidades de esa competitividad como una constante realidad en la UE (EC, 2004).

Pero concentrémonos en la dimensión territorial: ¿hasta dónde fueron capaces las políticas regionalistas impulsadas durante los últimos 15 años inspiradas en el NR- de avanzar hacia el mejoramiento de la cohesión territorial y la construcción de la Europa de todas las regiones?

Cierto es que el concepto de cohesión es impreciso, siendo frecuentemente presentado junto con la noción de convergencia (Begg, 1995) y asociado con las diferencias en la marcha del bienestar regional. Para analizar estas diferencias, se estandarizó el uso de indicadores liderados por el PBI per cápita a nivel regional, generalmente complementado con el de productividad ( $\mathrm{PBI}$ por trabajador) y el de la tasa de desempleo (Begg, 2003). Tomando estas variables como base para el análisis de la cohesión territorial: ¿qué han manifestado la UE y los principales aportes académicos sobre las asimetrías territoriales respecto de la búsqueda de un equilibrio territorial adecuado?

La EC asumió una posición ambivalente. En el Tercer Reporte sobre la Cohesión Económica y Social (2004) encontramos que, a diferencia de la preocupación por el crecimiento y la competitividad, la EC presentó un escenario optimista destinado a justificar sus políticas regionalistas. Así, pese a reconocer que las disparidades territoriales persisten y constituyen un problema, principalmente debido a la ampliación de la UE (EC, 2004:ix), se argumentó que esta nueva realidad estuvo marcada por un mejoramiento en la convergencia regional que prueba la efectividad de las políticas dirigidas a las LFR (EC, 2004:ix). Para sustentar esto se tomó una base nacional de análisis, comparando las asimetrías entre países, poniendo énfasis en los últimos años de los '90. El Reporte afirmó que-como resultado de la marcha exitosa de los países periféricos- se produjo una progresiva convergencia en el PBI per cápita, el empleo y la productividad (EC, 2004), sosteniendo que, al menos hasta 2001, las disparidades regionales en relación a esas variables se redujeron (EC, 2004:ix).

Pero al enfocar el análisis de las disparidades considerando las regiones -y no las naciones-, y en un período más extenso, la EC, a través de la Perspectiva de Desarrollo Espacial Europeo (ESPD) (1999) y de Reportes de Cohesión anteriores (2001; 2003a), manifestó una visión diferente que confluye técnica y argumentativamente con los más recientes aportes académicos.

Esta confluencia se constituye alrededor de los siguientes puntos:

- Muchos trabajos académicos y los Reportes de Cohesión 2001 y 2003 evidenciaron que -a diferencia de las predicciones neoclásicas (Barro; Sala I. Martin, 1991)- la convergencia regional y el proceso de decrecimiento de las desigualdades regionales, imperante durante la posguerra, sufrió un claro estancamiento desde finales de los '70 (Tondl, 2001; Cuadrado Roura, 2001; Molle; Broeckhout, 1995; EC, 2001; 2003a; Puga, 2002), asumiendo las asimetrías regionales dentro de la UE mayor significancia que aquellas que sobrellevan los Estados Unidos de Norteamérica o Canadá (López Baso et al., 1999; Boldrin; Casanova, 2001).

- Ofreciendo precisiones acerca de las disparidades interregionales en la UE concebida como un todo, López Baso demostró que -no obstante la equiparación en variables como la productividad laboral- no es posible encontrar convergencia regional en el PBI per cápita entre 1980 y 1992. Al considerar períodos más extensos (1989-1999), Puga (2002) y Rodríguez-Pose y Fratesi (2004) descubrieron que la tasa de convergencia es irrelevante cuando se aplica un análisis de convergencia b y el crecimiento es considerado en el modelo para eludir los problemas de autocorrelación espacial. Estos resultados confluyen con el Segundo Reporte de Cohesión Económica y Social (2002) y con los prove- 
nientes del ESDP (1999). Este último demarcó que las 25 regiones de la UE con el PBI per cápita más bajo sólo pudieron elevar el nivel del PBI per cápita en cuanto al PBI per cápita promedio de la UE desde un 52\% en 1986 a un 59\% en 1996 (ESDP, 1999:9). Por último, al analizarse las asimetrías regionales a través de la Desviación Estándar del PBI regional en la UE, se encontró un incremento del $20 \%$ en las disparidades regionales entre 1989 y 1999 (Rodríguez-Pose; Petrakos, 2004).

- Los resultados producen mayor preocupación si se analizan las disparidades regionales dentro de los países, al verificarse un crecimiento en las divergencias territoriales producto del mayor dinamismo de las regiones centrales bien conectadas con las redes europeas y globales-en relación con las periféricas (ESDP, 1999; Rodríguez-Pose; Fratesi, 2004; Puga, 2002; Duro, 2001).

- Ligado a lo anterior, se produjo un proceso de concentración económico-territorial en favor de las regiones centrales no sólo a nivel de los países, sino también dentro de la UE como un todo, al fortalecerse constantemente las regiones del área de Banana Azul. Según el ESDP, el área de la UE que incluye las metrópolis de Londres, París, Milán, Munich y Hamburgo, representando sólo el 20\% del territorio, concentraba aún en 1996 el 50\% del PBI de la UE (ESPD, 1999). El análisis espacial realizado por López Baso y otros (1999) mostró que ciertos cambios en la localización geográfica de clusters de alta producción en la UE no son suficientes para transformar estas estructuras centralizadas, y tampoco fue detectada ninguna tendencia clara a la difusión espacial de los procesos productivos complejos hacia las regiones periféricas. Contrariamente, se remarcó la emergencia de un club de convergencias (Quah, 1996) y una creciente polarización en dos clubs en el nivel de vida, que mantiene inalterada la división centro/periferia de la UE (López Baso et al., 1999). Por ello Cheshire y Magrini concluyen: "El cambio en el potencial económico resultante de la integración europea, con todo, tiende a reforzar los patrones de divergencia tanto entre el grupo de las regiones más pobres, como entre este grupo y las regiones más ricas" (Cheshire; Magrini, 2000).

- En cuanto a las desigualdades interregionales en las tasas de desempleo, pese a su reducción durante los '90 (Rodríguez-Pose, Petrakos, 2004; EC, 2004), la información exhibe una creciente polarización espacial como resultado del movimiento de las regiones con tasas de desempleo intermedias hacia los extremos (Esteban et al., 1999; Overman; Puga, 2002; Puga, 2002).

\section{Hacia una evaluación crítica de la estrategia de desarrollo del nuevo regionalismo en la UE}

\subsection{Explorando causas de la persistencia de problemas de cohesión territorial en el interior de las perspectivas del $N R$}

$\mathrm{Al}$ afrontar la explicación de las fallas en la obtención de una mayor cohesión territorial y elaborar una estrategia basada en una Europa para todas las regiones, compatible con la competitividad y el crecimiento, las instituciones europeas y el mundo académico comparten un aspecto básico que limita el diagnóstico y las estrategias alternativas: los elementos teóricos del NR básicamente son correctos y deberían inspirar una estrategia de desarrollo regional consistente para la UE.

Atento a ello, para la EC lo principal es atacar en las LFR sus “... .deficiencias estructurales en factores de competitividad claves - dotación inadecuada de capital físico y humano (infraestructura y habilidades de la mano de obra), falta de capacidad de innovación, de apoyo efectivo para negocios y un bajo nivel de capital ambiental-..." (EC, 2004:7). Como resultado de este diagnóstico, la propuesta oficial insiste en mejorar la coordinación institucional, simplificar la administración de los programas vigentes -situando a la eficiencia como el aspecto central- (EC, 2003b) y reforzar, en términos técnicos y presupuestarios, los programas orientados a la promoción de redes territoriales de conocimiento e innovación (EC, 2004). 
Desde la perspectiva académica no se manifestó una posición sustancialmente diferente de la de la EC. Estas contribuciones académicas trataron de incorporar a la perspectiva del NR los elementos originados en la nueva geografía económica (Krugman, 1991; Fujita et al., 1999) y la teoría del crecimiento endógeno (Romer, 1994). Y en la introducción de este parque conceptual, las "causalidades acumulativas" -fortalecidas centralmente por las especificidades históricas y los rendimientos crecientes a escala facilitados por la aglomeración-, fueron destacadas como unos de los factores principales para dar cuenta del constante refuerzo de las áreas centrales y el empeoramiento de la situación periférica de las menos desarrolladas (Puga, 2002; Chesshire, Magrini, 2000; Rodríguez-Pose; Fratesi, 2004; Thisse, 2000).

Desde este punto de vista, las críticas a las políticas regionales promovidas desde la UE no son estructurales y están constreñidas a resaltar los riesgos de reforzar el potencial de las regiones centrales con programas de infraestructura (Puga, 2002) y a destacar la importancia de priorizar la cualificación de los recursos humanos para fortalecer las LFR (Rodríguez-Pose, Fratesi, 2004). Sin embargo, estas propuestas no sólo no son alternativas, sino que se alinean con las últimas reformas promovidas por la EC, dirigidas a reforzar las redes de instituciones y PyME a nivel territorial. Aun más, estas contribuciones académicas se mostraron muy cautelosas al sugerir estrategias regionalistas pro-clusters mediante políticas públicas (Thisse, 2000); (Nooteboom, 1999). Mientras tanto, se reconoce que una estrategia general de redistribución a favor de las LFR es inoperable con el actual ordenamiento macro-económico de la UE (Hurst et al., 2000).

\subsection{Las fallas de la Estrategia Regionalista de la UE derivadas de las debilidades teóricas del $N R$}

Ante un escenario marcado por tres décadas de políticas de desarrollo regional-inspiradas en el NRy su ineficacia para revertir las asimetrías regionales y la creciente polarización económica y territorial de la UE, el análisis y explicación pueden tomar otro alcance, y una estrategia política diferente puede pensarse, cambiando la perspectiva analítica y poniendo en discusión los postulados teóricos y empíricos del NR adoptados por la UE.
Para presentar a las regiones como motores globales del desarrollo y ofrecer a dichas instancias como ámbitos estratégicos para combinar competitividad con cohesión social y territorial, la perspectiva del NR adoptada por la UE trabaja sobre dos premisas básicas:

- Desde la llamada trampa territorial (Agnew, 1994), la concepción de las regiones como cerramientos o entidades secuestradas (Amin, 2004a), capaces de decidir su propio destino, paradójicamente en un escenario dominado por un creciente entrelazamiento de las relaciones económicas, sociales y territoriales. Todo depende de una organización territorial adecuada, basada en redes (de CL y SRI) que permiten abandonar la concepción de las regiones como unidades ayudadas y transformarlas en nodos estratégicos y autorreproductivos, procurando la consecución de los objetivos de cohesión y competitividad de la UE.

- La configuración de las relaciones localesglobales en una única dirección, desde el escenario local hacia el global, lo que implica poder construir desde ese escenario el proceso global. Traducido al escenario europeo, desde las organizaciones y dinámicas regionales y locales -que incluye las LFR- es posible asegurar el crecimiento y la competitividad de la UE en el mercado global.

Pero la perspectiva del NR descuida dos elementos básicos acerca de los cuales existe una considerable evidencia: más que una dinámica global determinada por la emergencia de procesos regionales y locales que operan desde abajo hacia arriba, la realidad muestra procesos de transformación global que obligan a reconfigurar las formas organizativas y dinámicas locales. Las reglas, dinámicas, actores e instituciones globales y nacionales penetran permanentemente las realidades locales y regionales y tienden a crear múltiples desigualdades y subordinaciones que explican la persistencia y profundización de las asimetrías regionales.

Dada la importancia de entender la inconsistencia de estas asunciones del NR, es necesario analizar más cuidadosamente reglas, dinámicas, y actores del escenario de reproducción económico espacial de la UE, y articular esas asunciones a otras tres debilida- 
des centrales del NR: la aceptación pasiva de las reglas macro-económicas neoliberales y neoclásicas en el marco de desarrollo de dichas reglas, dinámicas y actores; la dilución del Estado nacional, y la desaparición de los modelos nacionales de desarrollo.

\subsubsection{Reglas macroeconómicas bajo el dominio neoliberal. ¿Equilibrio y ambiente favorable para el desarrollo regional global?}

El NR y las políticas regionalistas de la UE comparten su visión sobre las reglas macroeconómicas de la agenda neoliberal y de los instrumentos económicos neoclásicos dirigidos y restringidos a alcanzar un equilibrio fiscal y económico para controlar la inflación y crear las condiciones para un crecimiento sustentable. Estas reglas macroeconómicas serían el marco general para crear ambientes apropiados donde desarrollar procesos productivos competitivos.

No obstante, mientras estos postulados globales son aceptados y dichos atributos son concedidos a los instrumentos neoclásicos y neoliberales, el NR considera que el mainstream macroeconómico es incapaz de comprender adecuadamente los niveles meso, donde se despliegan los procesos productivos. Por lo tanto, usando una estructura conceptual específica -diferente de la neoclásica- se sustenta la necesidad de evaluar las cualidades de la aglomeración, la cooperación/coordinación interinstitucional e interempresarial a nivel territorial (Scott, Storper, 2003) y luego promover a nivel territorial patrones organizacionales y funcionales de SRI y CL para alcanzar una competitividad que el mercado y los instrumentos neoclásicos no pueden generar por sí mismos. Asumiendo dicha perspectiva, las políticas regionales de la UE adoptaron un rol meso-complementario respecto de la estrategia macroeconómica de base neoliberal, sosteniendo que con ella todos los territorios de la UE pueden tomar ventaja de esta lógica local-global sólo cualificando su consistencia organizacional y funcional interna. Más allá de las condiciones globales y de las diferencias estructurales, desde que estas acciones regionalmente autoorganizadas pasan a ser emprendidas por las LFR, la superación de las asimetrías territoriales puede hacerse una realidad.

Sin embargo, la evidencia empírica aún muestra una falla básica en estas premisas del NR: las reglas macro de la agenda neoliberal no sólo promueven salud fiscal y monetaria, sobre la que descansa la posibilidad de crear -desde el nivel mesocerramientos regionales organizados alrededor de redes horizontales y territoriales, sino que también estimulan la consolidación y expansión de un patrón de acumulación direccionado hacia una mayor concentración en torno a un grupo selecto de actores económicos y territoriales.

Más precisamente, los procesos competitivos no se producen en un mercado horizontal gobernado por PyMES organizadas en nichos territoriales, sino en redes mutables e inestables que operan globalmente y penetran de una manera selectiva diferentes dinámicas locales. Estas redes quedaron crecientemente bajo el control de las grandes (ET), que consolidaron en el contexto europeo "gigantescos complejos internacionales de producción" (Amin, 2000). Aun cuando es cierto que dicho proceso de concentración se generó antes de la conformación de la Unión Monetaria (EMU) (Amin, 2000), también lo es que se reforzó con la consolidación de reglas macroeconómicas de la UE apoyadas hegemónicamente y custodiadas por el capital global representado por las ET.

Desde entonces, y ante la expansión de las redes de flujos translocales y transregionales (Castells, 1996; Amin et al., 2003), los actores trasnacionales afianzaron su posición y control sobre dichas redes en toda la UE con reglas de funcionamiento macroeconómico que promueven: un constante crecimiento de libertad negativa transferida desde las áreas institucionales estratégicas hacia una elite de policy-makers asociados a las ETs; una competencia regional y nacional creciente por inversiones provenientes de esos grandes complejos empresariales, y un amplio espectro de fusiones y adquisiciones entre grandes actores, en su mayoría no originariamente pertenecientes a la UE (Bailey et al., 1999; Dicken et al., 1994).

Esta creciente dinámica de concentración al nivel de actores macroeconómicos trajo consecuencias espaciales opuestas a la perspectiva del NR respecto de la posibilidad de configurar la dinámica global y combinar cohesión y competitividad con un proceso desde abajo hacia arriba, formado por el protagonismo colectivo de los "cerramientos" regionales/locales. 
$\mathrm{Al}$ romper con los patrones económico-espaciales del fordismo y promoverse una economía europea con geometría variable (Zysman, Schwartz, 1998), los capitales concentrados y transnacionales usaron la dinámica de las redes y las nuevas tecnologías para fortalecer su capacidad de penetrar, desde estrategias extrarregionales, diferentes territorialidades, adaptando los patrones económicos e institucionales regionales a sus lógicas de reproducción centralmente controladas (Dunning, 1993). Importantes aportes académicos mostraron cómo, en la UE, las ET dominantes capitalizaron en sus estrategias la combinación de concentración y la descentralización. En relación con el primer aspecto, las formas más sofisticadas de producción con altos volúmenes fueron confinadas en regiones selectasBanana Azul-, en general pertenecientes a los países centrales de la UE, donde se concentran los principales tomadores de decisión, así como los más relevantes recursos a nivel de Innovación y Desarrollo (I+D) (Hudson, 1998b). Al mismo tiempo profundizándose con la incorporación del Este de Europa- las ET capitalizaron las estrategias de reproducción en red al descentralizar en las regiones periféricas actividades productivas que no están orientadas a la consolidación de las capacidades endógenas de la economía local con redes horizontales sino a subordinar respecto de regiones y actores centrales, y mediante la subcontratación, gran número de PyME con baja capacidad de generación de valor y escaso enraizamiento territorial (Hudson, 1998a-b; 2003; Amin; Tomanney, 1995).

Por lo tanto, a las viejas inercias vinculadas a formas débiles de cooperación local, instituciones frágiles y el dominio de formas organizativas verticales, las LFR han debido enfrentar ahora -bajo la EMU- los efectos de reglas macroeconómicas que consolidaron patrones de acumulación basados en redes extrarregionales/locales asimétricas -dominadas por las ET-. La realidad mostró que dichas reglas no sólo promueven el reforzamiento de determinados centros territoriales claves, sino que también subordinan la lógica reproductiva de las áreas periféricas a estos centros, bloqueando sus estrategias de desarrollo endógeno.

Con estas condiciones, parece poco plausible presentar a regiones y localidades-especialmente las LFR- como cerramientos con protección inmunológica a las dinámicas externas y con capacidades para desarrollar competitividad y cohesión en una forma territorialmente generalizada, mediante una vía única de lo local a lo global.

\subsection{2. ¿Desarrollo de las regiones bajo la dilución del Estado nacional?}

Junto a esta posición irrealista, la perspectiva del NR y las políticas de desarrollo regional europeas presentan una segunda cuestionable asunción: la dilución del Estado nacional. Bajo el esquema interpretativo local-global empleado para entender el nuevo reposicionamiento del capitalismo (Swyngedouw, 2000), y la tendencia a focalizar el desarrollo local-global a través de una sociedad civil autogobernada, la perspectiva del NR no sólo perdió al Estado en sus consideraciones (Mac Leod, 2001), sino que terminó cercana a los aportes académicos que sostienen la disolución del Estado nacional (Omhae, 1996). En consecuencia, la UE le ha otorgado al Estado nacional un rol menor en las políticas regionales, apareciendo más recientemente sus funciones restringidas a mejorar la coordinación multigobierno en un escenario de creciente relevancia de los programas supranacionales (EC, 2004; 2003a; Begg, 2003).

Cierto es que, dado el re-escalonamiento de la estatidad en la era postfordista, el Estado nacional no es concebible como un container territorialmente delimitado desde el cual se puede regular y legislar la mayoría de las actividades socioeconómicas (Brenner, 2003a; Sassen, 2003). Sin embargo, continúa desplegando un claro rol político-económico dentro del proceso de globalización (Weiss, 1998; Evans, 1995) y no es su disolución lo que ocurre, sino un proceso interactivo y complementario con el proceso globalizador, en el cual emergen particularidades que lo debilitan y otras que lo fortalecen (Mann, 1997).

Esta presencia activa y coproductiva del Estado nacional se aprecia claramente en la UE, pues, pese a las fuerzas de re-escalonamiento ascendente y la consolidación de nuevas instituciones supranacionales, dicha instancia institucional aún retiene instituciones e instrumentos presupuestarios de enorme importancia, pudiendo formular políticas públicas con fuertes efectos socioeconómicos sobre todas las regiones y localidades europeas. En términos cuanti- 
tativos, basta indicar que, mientras el Estado nacional dicta políticas públicas utilizando presupuestos equivalentes a valores de entre el $40 \%$ y el $60 \%$ del PBI nacional, el presupuesto de la UE es de sólo el 1,2\% de su PBI (Markopouliotis, 2002), siendo los recursos asignados a las políticas regionales para paliar las asimetrías territoriales tan sólo el 0,5\% del PBI de la UE (EC, 2003a).

En este contexto -confirmando el significativo rol de los Estados naciones en la estratificación de los procesos supranacionales (Mann, 1997)-, la UE muestra que los Estados nacionales de los países centrales -esencialmente Francia y Alemania-gozaron de un poder geopolítico destacable dentro de la Comunidad Europea (Mann, 1997:15) que, en acuerdo con el capital global, les permitió ocupar una posición privilegiada en el manejo de instituciones claves como el Banco Central Europeo (Cameron, 1995) y eludir las reglas impuestas a los miembros más débiles de la UE (Hudson, 1998b). Desde esa posición, estos Estados nacionales poseen la capacidad de impulsar políticas que refuerzan las disparidades interregionales al alentar la generación y direccionamiento de flujos económicos y tecnológicos hacia las regiones centrales dentro de su soberanía. Respecto de las desigualdades regionales intra-países, los Estados nacionales - compelidos por la necesidad de atraer inversiones y mejorar la competitividad-han usado instrumentos (como el apoyo de políticas tecnológicas, infraestructuras básicas y promoción de nuevos complejos de servicios) que beneficiaron a los principales centros regionales en detrimento de las regiones periféricas (EC, 2003a).

Consecuentemente, producto de su errónea asunción de una progresiva disolución del rol del Estado nacional, el NR -y los formuladores de políticas inspirados en él- no parecen capaces de captar la forma en que las asimetrías regionales y las desigualdades territoriales fueron impulsadas por importantes factores enraizados en la presencia del Estado nacional y en su, aún relevante, intervención.

\subsection{3. ¿Desarrollo regional a expensas de la pérdida de las trayectorias nacionales?}

Una tercera asunción es que las trayectorias nacionales y el papel de los modelos nacionales de desarrollo, alrededor de los cuales se conformaron las dinámicas y realidades regionales, acompañaron la dilución del Estado nacional en la pérdida de relevancia.

Sin embargo, la globalización no se configuró como un proceso homogéneo, que ofrece a todas las regiones posibilidades de alcanzar competitividad internacional y cohesión social/territorial con fuerzas que operan desde abajo hacia arriba, sino que lo hizo sobre la base de dinámicas multiescalares, que llevan a los sistemas sociales de producción a generar una amplia gama de respuestas (Hollingsworth, 1998). Esas heterogéneas y multiescalares respuestas son dependendientes de los patrones institucionales y de comportamiento previamente configurados en cada país, los que condicionan los repertorios que receptan y configuran el proceso globalizador (Sassen, 2003).

En la construcción de las trayectorias nacionales se involucran distintas formas de coordinación institucional entre el capital y el trabajo, modalidades dominantes de capital (financiero y productivo) y formas cuantitativas y cualitativas de intervención estatal (Hollingsworth; Boyer 1997; Crouch; Streek, 1997). Desde un punto de vista general, y reforzando una línea de investigación que explora las configuraciones socioinstitucionales y los resultados socioeconómicos de los modelos nacionales, Hall y Sosckie distinguieron dos modelos básicos: las Economías de Mercado Liberal (EML), representadas principalmente por EEUU y Gran Bretaña (GB), donde el mercado es el factor clave en la coordinación entre empresas y trabajadores y entre el capital financiero y productivo; las Economías de Mercado Coordinado (EMC), representadas esencialmente por la experiencia alemana y caracterizadas por acuerdos de largo plazo entre empresas y trabajadores por formas ajenas a la libre regulación del mercadoy por la hegemonía del sistema bancario en el sector financiero. Complementariamente, Bruno Amable identificó, junto a las EML, tres modelos más: el Social-demócrata, representado por los países escandinavos; el de la Europa Continental, representado por Alemania y Francia, y el Mediterráneo, expresado por España, Portugal y Grecia (Amable, 2004). Aunque estos modelos fueron reconocidos por las instituciones de la UE en la preparación del Tercer Reporte-concentrado en el rol del Estado nacional en la cohesión territorial (EC, 2003a)-, dicho reco- 
nocimiento sólo se hizo de manera puntual y aislada, siendo excluido del Reporte Oficial de 2004.

Pero la identificación y comparación de estos modelos nacionales resulta central, pues la presencia y funcionamiento de cada uno son relevantes para examinar las respuestas territoriales a la globalización y el diferencial desempeño y bienestar alcanzados a nivel de naciones y de regiones. No casualmente su análisis cobró un destacado papel al debatir crítica y comparadamente la performance de la UE y el modelo a seguir.

Promovido por la cúpula institucional de la UE -hegemonizada por la macroeconomía neoclásica asociada al capital global-el Reporte Sapir solicitado por la presidencia de la UE (Sapir, 2003) resaltó las virtudes del modelo neoliberal de EEUU -excluyendo curiosamente GB- para atacar las debilidades competitivas de la UE a nivel mundial. Siguiendo este espíritu, el Reporte destacó la necesidad de desarrollar un nuevo paquete de reformas dirigidas principalmente a la incorporación de estrategias de desregulación y de competencia para consolidar el mercado único y remover los obstáculos del modelo institucional europeo para alcanzar la competitividad. En línea con ello, y valiéndose de los modelos de Hall y Soskice, Casey reunió numerosas medidas relativas a factores de demanda y de oferta (incluyendo tasa de crecimiento del PBI, PBI per cápita, desempleo y productividad) para afirmar que, en un escenario de intensificación de la globalización, el desempeño de los países vinculados a Economías de Mercado Coordinado (EMC) se deterioró respecto de aquellos ligados a Economías de Mercado Liberal (EML) (Casey, 2004).

Sin embargo, en su estrategia comparativa, el trabajo de Casey y el Sapir Report excluyeron a los países escandinavos representantes del modelo socialdemócrata. Aunque éstos (Suecia, Finlandia, Noruega y Dinamarca) fueron en la última década exhortados a desmantelar el Estado de Bienestar, la modificación de su modelo fue muy lenta (Borgaza; Maiello, 1997), preservando una cobertura social universal, políticas distributivas e igualitarias y una fuerte implicación estatal compatible con patrones de cooperación entre el sector público y el privado en el área social y productiva (Asheim, 2000b).

Con variables similares, Amable demostró que los países escandinavos -sustentados en la alta cohe- sión social e implicación institucional- no sólo no tuvieron un desempeño menor, sino que mostraron un mejoramiento que los acercó a los niveles de competitividad de EEUU sin sacrificar los principios de protección social e intervención estatal (Amable, 2004). Igualmente, trabajando comparativamente los niveles de competitividad de EEUU y Dinamarca, Beng Lundvall encontró ventajas en el modelo socialdemócrata, demostrando que las dinámicas de innovación vinculadas a un crecimiento y una productividad sustentables se correlacionan con la cohesión territorial promovida desde el nivel nacional (Lundvall, 2002). Estos resultados, a contramarcha de las propuestas neoliberales, reafirman las demandas previas a las políticas europeas para que consideren políticas nacionales socialmente integradoras, sustentadas en la inversión en recursos humanos y en el continuo mejoramiento a nivel colectivo-organizacional como condiciones para establecer bases reales de competitividad (Andreassen et al. 1995; Dosi, 1997; Coriat, 1997).

Ahora bien, las respuestas y resultados provenientes de los modelos nacionales no sólo se limitan a la competitividad y a la integración social, sino que se vinculan al proceso de desarrollo regional e integridad territorial. Trabajando sobre el desarrollo económico regional basado en la producción petrolera, y contrastando el modelo socialdemócrata/escandinavo de Finlandia con la trayectoria neoliberal de GB, Cumbers mostró cómo estrategias nacionales con patrones de implicación estatal diferentes provocan resultados regionales diversos (Cumbers, 2000). Su aporte destacó que, en el marco del creciente proceso de globalización de la producción, mientras las políticas petroleras de GB priorizaron al mercado internacional y estimularon una alianza con las redes multinacionales en detrimento del capital basado en la trilogía nacional-regional-local, las políticas petroleras de Finlandia se dedicaron a desarrollar un cluster petrolero intranacional para fortalecer a los oferentes internos (Cumbers, 2000).

Patrones diferenciados de respuestas, como el indicado, mostraron importantes consecuencias al considerar, en un nivel agregado, la integridad territorial y las asimetrías regionales en cada país. Basándose en las diferencias en el PBI Regional, el Gráfico № 1 permite observar contrastadamente las menores disparidades entre las regiones más ricas y más pobres 
Figura 1. PBI Per Capita Reino Unido y Países escandinavos - 2001*

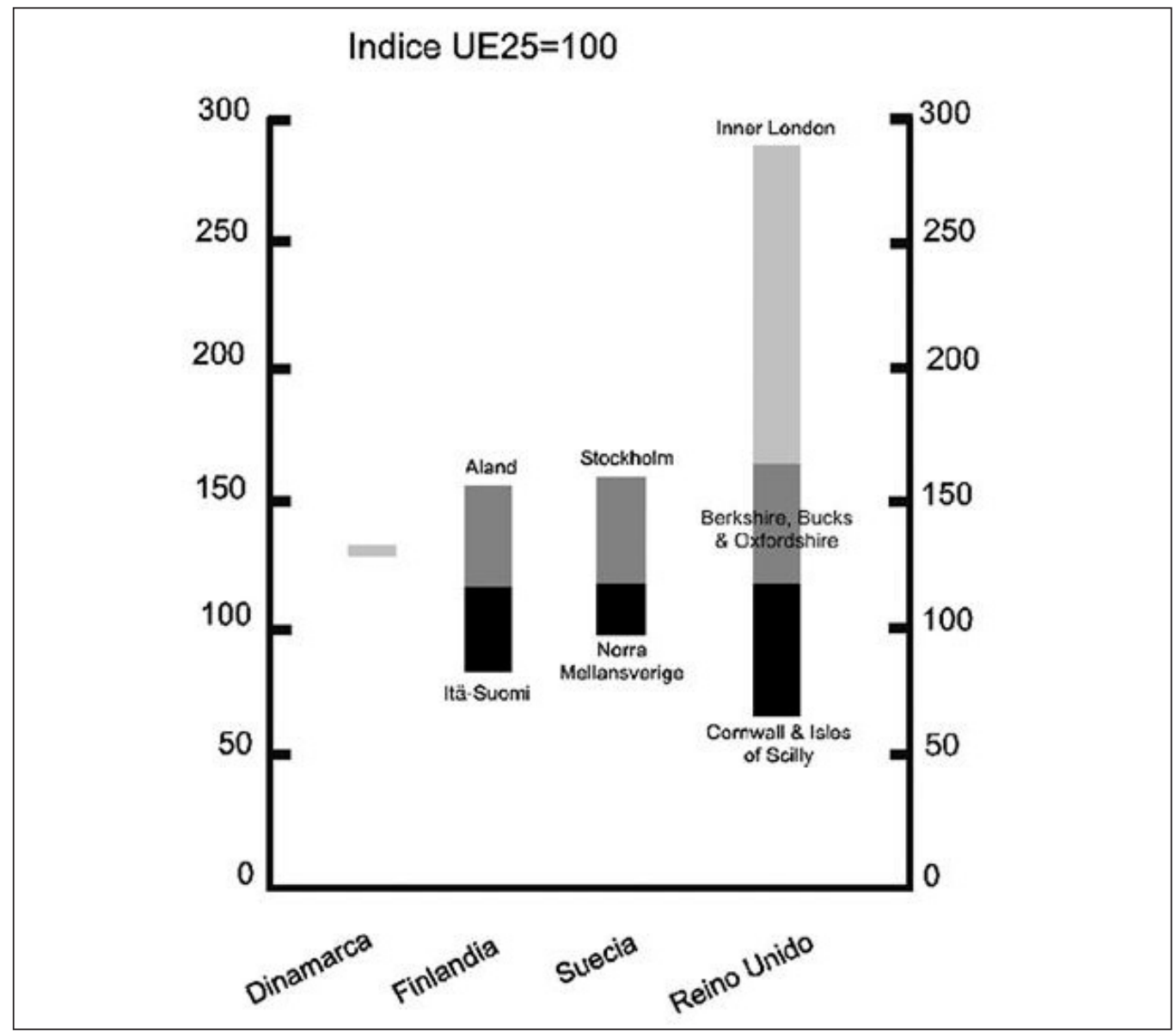

${ }^{*}$ La información de Noruega no fue encontrada en la base de datos de Eurostat.

Fuente. Eurostat

exhibidas por los países escandinavos en relación con el neoliberal modelo de GB, donde esa disparidad se presenta como la más importante de la UE.

Desafortunadamente, este cuerpo de elementos vinculados a los modelos y trayectorias nacionales fue suprimido de la perspectiva del NR, limitando la capacidad de entendimiento de las desigualdades regionales y la posibilidad de pensar en alternativas regionales más integradoras.

\subsection{Rearticulación de las debilidades del NR en las políticas de la UE. Evaluación de sus consecuencias}

Permítasenos rearticular las debilidades centrales del NR con el fin de evaluar más holísticamente sus efectos sobre las políticas de la UE y asimilar elemen- tos para enfrentar el desafío de generar una estrategia de desarrollo regional más consistente.

Dos asunciones son primariamente constitutivas de la debilidad del NR: la definición de las regiones y localidades como cercamientos e instancias de desarrollo autorreproductivas y la idea de un nuevo escenario global-local sobre el cual construir -en una única dirección- procesos de desarrollo desde abajo hacia arriba para alcanzar el doble objetivo de la competitividad europea a nivel global y de la cohesión territorial. Sobre esta concepción, el NR presenta serias dificultades para comprender cómo dinámicas, actores y trayectorias institucionales que operan desde afuera -desde los niveles globales y nacionales- penetran las realidades regionales-locales de manera asimétrica, reproduciendo y expan- 
diendo las desigualdades territoriales. Sobre estas limitaciones se asientan otras presunciones, tampoco bien fundadas, que alientan una aceptación pasiva de los fundamentos económicos promovidos por el mainstream que controla las instituciones macroeconómicas de la UE y sus promesas de favorecer con su funcionamiento el equilibrio y la convergencia económica, social y territorial. Como resultado, el marco teórico y las estrategias de desarrollo del NR aplicadas en la UE, actuando complementariamente respecto de las instituciones y programas macroeconómicos, quedaron restringidos al nivel meso, formando parte de un juego global en el que los cercamientos locales y regionales no tienen la autonomía necesaria para enfrentar la dinámica global de redes y la creciente concentración que, promovida por aquellas instituciones macroeconómicas, constantemente penetran y modifican los procesos locales de reproducción.

De este modo, las estrategias territoriales terminan siendo cómplices de una dinámica que fortalece la posición de las regiones centrales y agrava la situación periférica de las regiones más atrasadas. Paradójicamente, el NR está jugando funcionalmente con una estrategia general que profundiza regresivamente las asimetrías que intenta revertir. Si avanzamos, observamos que la perspectiva del NR y las políticas de desarrollo regional promovidas por la UE se hacen funcionales al interés del capital global, sobre el cual se asientan las instituciones claves del proyecto neoliberal y se manejan las variables macroeconómicas.

Efectivamente, la promoción de la competitividad desde las estrategias de desarrollo desde abajo hacia arriba, centradas en el fortalecimiento de cerramientos intrarregionales que compiten entre sí, opera casi exclusivamente apuntando al interés del capital global debido a dos razones básicas: a que bajo dicha dinámica se consolida un proceso fragmentario de reproducción socioterritorial que expande la libertad de acción del capital global, al reducirse la posibilidad de operar centralizadamente desde el Estado nacional una presión sobre el mismo orientada a extraer ingresos (Lake, 2002) con los que impulsar mecanismos de redistribución en favor de los actores endógenamente posicionados a nivel nacional y regional. $Y$ en forma complementaria, en un entorno neoliberal de expansión de la competencia interregional (Brenner, 2000), la mez- cla de estrategias desde abajo hacia arriba, competencias interregionales y autoorganización territorial contribuye a impulsar islas de competitividad, comprometidas a ofrecer al capital global un ambiente institucional, social y económico cualificado, alcanzando estos objetivos sin demandar recursos directos del Estado e indirectos - a través de ingresos impositivos- del capital global.

Al mismo tiempo, al analizar la perspectiva del NR y las políticas regionales de la UE sobre esta lógica funcional, la doble desconsideración del Estado nacional y el papel de las trayectorias/modelos nacionales acarrea dos consecuencias relevantes: refuerza la incapacidad de comprender el origen real y estructural de las desigualdades regionales y conduce a la pérdida de dos elementos estratégicos al momento de re-pensar, re-cualificar y re-definir el NR y las políticas estructurales de desarrollo.

\section{Conclusiones: desde el diagnóstico de las debilidades a la redefinición del NR y las políticas de desarrollo regional. Desafíos para la UE y enseñanzas para América Latina}

Permítasenos, finalmente, rearticular las debilidades mencionadas con nuestros interrogantes iniciales para luego sugerir algunas ideas destinadas a introducir mejoras en la perspectiva del NR y avanzar en una estrategia regionalista alternativa.

Asumiendo desde los inicios una perspectiva latinoamericana, e intentando encontrar elementos de inspiración para el proceso de integración de $\mathrm{AL}$, comenzamos este trabajo preguntándonos si el NR dominante en las políticas territoriales de la UE-a partir de su matrimonio con el hegemónico proyecto neoliberal- ha sido capaz de confrontar y revertir las asimetrías territoriales y de construir una Europa para todas las regiones.

Nuestra repuesta va en dirección opuesta a la confianza oficial de la UE respecto de la posibilidad de compatibilizar-desde dicho matrimonio- la cohesión social y territorial con la mejora de la competitividad. Sostuvimos que, pese a los continuos esfuerzos presupuestarios y programas de expansión que apoyan dicha confianza, las políticas regionales inspiradas en el NR colisionaron con la persistencia y la expansión de las desigualdades re- 
gionales y fracasaron a la hora de fortalecer las LFR y permitirles alcanzar o aproximarse a la dinámica de las regiones centrales. También destacamos que, curiosamente, al explicar estas desigualdades persistentes y ofrecer alternativas, la posición oficial de la UE y las voces más renombradas de la esfera académica insistieron en emplear las herramientas del NR asociándolas a la nueva geografía económica y a la teoría del crecimiento endógeno-, para concluir mostrando extremada cautela al sugerir políticas.

Si tomamos seriamente el argumento presentado en este trabajo, podemos sostener que, si hay algo que AL puede aprender de la estrategia de desarrollo regional de la UE es que no existe nada parecido a un modelo a replicar o en el cual inspirarse, y que, desde una perspectiva territorial dinamizadora e inclusiva, "ningún cambio significativo parece posible sin la formulación de una narrativa alternativa" en la estrategia de construcción europea (Petrella, 2000).

Esta afirmación coloca sobre la mesa de la UEy de la de AL- el desafío de avanzar sobre los límites del NR, superando sus debilidades estructurales originadas en asunciones erróneas sobre las cuales se construyó el matrimonio con la estrategia neoliberal de la UE.

Para ello es preciso remarcar que, adoptando la concepción autorreproductiva del territorio perteneciente al NR, las políticas de desarrollo territorial de la UE delegaron en las instancias regionales periféricas la responsabilidad de revertir por sí mismas su relegamiento mediante estrategias de cualificación endógenas y así contribuir al equilibrio territorial y a la competitividad de la UE como un todo. Insistimos en que este posicionamiento, acoplado a la estrategia neoliberal y a las demandas del capital global, resulta altamente inefectivo y regresivo en cuanto a la integración territorial.

En relación con este último aspecto, cabe resaltar que, desde su asentamiento sobre esa concepción del territorio como cerramientos autorreproductivos propia del NR, las políticas regionales de la UE son incapaces de responder: ¿por qué las regiones más atrasadas y empobrecidas, dominadas por instituciones colectivas débiles, comportamientos free riders, baja calificación de los recursos humanos y programas de apoyo con un presupuesto de tan sólo el 0,5\% del PBI de la UE, podrían generar formas autoorganizadas de desarrollo aun difíciles de visualizar en los ámbitos social e institucionalmente más avanzados? ¿¿Fundado en qué elementos podría pensarse que esas regiones crecientemente periféricas podrían llevar adelante innovaciones a nivel de los procesos productivos en forma más eficiente que los centros territoriales más dinámicos, favoreciendo así la convergencia de la UE? ¿Por qué todo ello podría transformarse en una realidad en un macro-contexto donde la concentración dentro de redes multiescalares y una implicación fuerte del Estado nacional consolidan una UE territorialmente desigual?

Anticipando una respuesta general, Amin ha sostenido: "Sin prestar atención a las más amplias circunstancias institucionales y del mercado que modelan los destinos locales, las estrategias focalizadas desde la comunidad nunca serán más que un engaño para las altamente presionadas ciudades y regiones, posiblemente sólo sean un paño frío, en tanto que el apoyo brindado por el Estado de Bienestar y otras medidas redistributivas son sutilmente retiradas en nombre de un perspectiva basada en el empowerment de la comunidad, dejando que 'la porción del león' de políticas y acuerdos institucionales para el desarrollo económico nacional permanezca sesgada hacia las ciudades y regiones más prósperas" (Amin, 2005).

Este argumento no significa necesariamente que la cualificación de la autoorganización regional no sea útil y relevante, sino que las ventajas participativas y flexibilizadoras derivadas de dichas estrategias desde abajo hacia arriba -con alta revalorización de la aglomeración territorial-necesitan ser ubicadas en el contexto de dinámicas multiescalares que, en gran medida, se configuran desde lo global y recaen sobre las regiones fomentando desigualdades entre y dentro de ellas. Por lo tanto, se requiere desarrollar nuevas herramientas basadas en la redefinición de las relaciones macro-meso, reconociendo a "las regiones y localidades como partes de sistemas económicos, redes y flujos de recursos más amplios antes que como unidades autocontenidas y cerradas" (Turok, 2004). Luego, debemos reconocer a la UE como un espacio translocal, constituido y atravesado por "sistemas económicos y flujos de recursos" donde los actores económicos e institucionales más fuertes y concentrados promueven dinámicas económicas y territoriales selectivas. 
Atender a este marco alternativo de interpretación -y en línea con el argumento antes desplegado- implica asumir que son básicamente estas dinámicas y fuerzas asimétricas y concentradas - y no la débil competitividad de las localidades más pobreslas principales razones involucradas en la reproducción del actual "Archipiélago Europa" (Petrella, 2000), formado por pequeñas "islas centrales" rodeadas por un mayoritario y creciente grupo de regiones que operan algunas en forma subordinada y otras excluidas (Agnew, 2001).

Dando lugar al anterior marco de interpretación, el segundo gran paso consiste en extraer al NR de su confinamiento en el nivel micro-meso y asumir el desafío de discutir las condiciones macroeconómicas e institucionales para alcanzar un desarrollo regional integral. Para ello es necesario abandonar la aceptación pasiva de las reglas macroeconómicas neoliberales y el rol complementario adjudicado a, y asumido por, el NR. Dicha rediscusión no excluye la redefinición de las principales reglas de Maastricht centradas en restricciones fiscales y monetarias. Esto significa que, preservando una administración macroeconómica equilibrada y eficiente, pero en dirección opuesta a las propuestas desreguladoras y privatistas del Reporte Sapir, una estrategia de desarrollo regional integral necesita recuperar a favor del Estado márgenes de acción fiscales y monetarios para dar a las instituciones nacionales y supranacionales capacidad para generar acuerdos regionales inclusivos y redistributivos.

Para ser posibles y operativos estos nuevos acuerdos, se requiere considerar seriamente los aspectos más positivos de dos elementos subestimados por el NR: las trayectorias y modelos nacionales de capitalismo y el Estado nacional. En vista de lo ya señalado, parece claro que ambos elementos necesitan ser recuperados estratégicamente para identificar vínculos con la generación de desigualdades territoriales y para establecer una propuesta regionalista alternativa.

Respecto de la relevancia de los modelos de $\mathrm{Na}$ ción, la compatibilidad entre cohesión social y territorial y una buena performance económica, mostrada por el modelo escandinavo, invitan a pensar-sin subestimar las especificidades locales/nacionales-la relevancia de establecer reglas universales de cobertura social y mecanismos agregados de acuerdo entre el capital y los trabajadores en los niveles supranacionales europeos (y latinoamericanos). Asimismo, para orientar recursos hacia la cobertura social y cualificar las condiciones territoriales de producción en todas las regiones de la UE es necesario reintroducir en el escenario supranacional un mejoramiento y aumento de las rentas a tributar por el capital económica y territorialmente más concentrado. Por último, es fundamental establecer condiciones y restricciones supranacionales comunes a la movilidad del capital para contribuir a la redefinición del perverso mecanismo creado por complejas redes en las cuales las regiones centrales pueden subordinar y explotar a los territorios más pobres con mano de obra barata.

Es importante destacar que todos estos acuerdos supranacionales - con inspiración socialdemócratano están dirigidos a disminuir la importancia del Estado nacional. Contrariamente, luego de la fragmentadora experiencia de la UE con el NR, esta instancia institucional pareciera ser la más adecuada (Lake, 2002) para implementar a nivel territorial -y en coordinación con el nivel supranacional- estrategias integrales e integradoras orientadas, desde el lado de la demanda, a coordinar con las instituciones supranacionales la protección de los derechos sociales en todas las localidades y regiones, y desde el lado de la oferta, a ofrecer apoyo real con los programas de integración nacional, garantizando recursos para desarrollar un patrón colectivo de articulación entre los grupos industriales e institucionales de las LFR.

Ciertamente, esta importancia del Estado nacional no debe confinarse a los países periféricos, sino ser aprehendida por los países centrales, como Gran Bretaña. En ellos, en un contexto de demonización de la centralización (Walker, 2002), la descentralización y el nuevo localismo se implicaron en la ampliación de las desigualdades regionales y en una reconcentradora lógica de reproducción económica y social (Amin et al., 2003). Pero, dadas las asimetrías entre los Estados nacionales y la importancia de éstos en la configuración y reforzamiento de las desigualdades interregionales, es preciso implementar desde el nivel supranacional programas dirigidos a fortalecer las capacidades del Estado nacional de los países periféricos.

Aunque observando todos los elementos implicados en esta línea de transformación, sería ingenuo creer que este gran desafío puede concretarse a través 
de la voluntad política o aun con una posición académica compartida sin considerar los intereses y fuerzas sociales involucrados y afectados por esta propuesta. $\mathrm{Al}$ respecto hemos resaltado que -más allá del discurso oficial- el proyecto de la UE que está en marcha se orienta a la consolidación de un grupo concentrado de actores económicos y políticos -bajo la hegemonía del capital global- que necesita subordinar la integración regional (o la cohesión territorial) al proyecto neoliberal que emplea la competencia/competitividad multiescalar y regional como plataforma de un perfeccionamiento económico selectivo. En consecuencia, ciertas cuestiones emergen inmediatamente para introducir nuevos elementos en un camino diferente hacia el desarrollo regional: ¡será la UE capaz de construir una coalición social alternativa y de generar una elite política e institucional-apoyada por los niveles regional y nacional- con capacidad real para materializar el desafío de revisar sus principios marcoeconómicos centrales y adaptarlos a un escenario donde sea posible mejorar la competitividad dentro de una dinámica regional integral e integradora? ¿Será AL capaz de resistir la tentación de copiar modelos y de aprender críticamente de la trayectoria europea de desarrollo regional?

\section{Referencias Bibliográficas}

Agnew, J. (1994). “The Territorial Trap: The Geographical Assumptions of International Relations Theory", Review of International Political Economy, 1, 53-80.

(2001). "How Many Europe? The European Union, Eastward Enlargement and Uneven Development", European Urban and Regional Studies, 8(1), 29-38.

Amable, B. (2004). "Reforming Europe: Is The Third Way The Only Way?", Prisme, 3, Centre Saint-Gobain pour la Recherche en Economie.

Amin, A. (1995). "Post-Fordism: Models, Fantasies and Phantoms of Transition", Amin, A. (ed.), Post-Fordism, A Reader, Blackwell, 1-39.

(1999). "An Institutionalist perspective on regional economic development", International Journal of Urban and Regional Research, 23, 365-378.

(2000). "The European Union as more than a Triad Market for National Economic Spaces", Gordon, C. et al. (eds.), The Oxford
Handbook of Economic Geography, Oxford University Press, 671-688.

(2004). "Regions Unbound: Towards a New Politics of Place", Geografiska Annaler, 86 (B), 33-43.

(2005). "Local Community on Trial". Economy and Society 34(4), 612-633, November.

Amin, A, Massey, D \& Thrift, N. (2003). "Decentering The Nation. A Radical Approach to Regional Inequality", A Catalyst Paper, 8 , London: Catalyst.

Amin, A \& Tomaney, J. (1995). "The Challenge of Cohesión”, Amin y Tomaney (eds.), Behind The Myth of European Union, Prospects for cohesion, Routledge, 10-47.

Andreasen, L., Coriat, B., Den Hartog, F. y Kaplinsky, R. (1995). Europe's Next Step - Organisational Innovation, Competition and Employment. London: Frank Cass.

Asheim B. (1999). "The Territorial challenge to innovation and endogenous regional development", Coling (ed.), Industrial Policy in Europe. Theoretical perspectives and practical proposals, Routlege-l'institute, 58-73.

(2000a). "Industrial Districts: The Contributions of Marshall and Beyond", Gordon, C. et al. (eds.), The Oxford Handbook of Economic Geography, Oxford University Press, 413-431.

(2000b). The Learning Firm in the Learning Region: workers Participation as Social Capital, DRUID-Summer 2000 Conference, Rebild, Denmark, June, 15-17.

Bailey, D., Harte, G. \& Sugden, R. (1999), "Regulating Transnationals: free markets and nomitoring in Europe", Coling (ed.), Industrial Policy in Europe. Theoretical perspectives and practical proposals, Routlege-l'institute, 311-325.

Barro, R. J. \& Sala-I-Martín, X. (1991). "Convergence Across States and Regions", Brooking Pap. Econ. Activity, 1, 107-182.

Batt, J. \& Wolczuk, K. (eds.) (2002). Region, States and Identity in Central and Eastern Europe, London: Frank Cass.

Becattini, G. (1992). "El distrito industrial marshalliano como concepto socioeconómico"; Pyke et al. (eds.), Los distritos industriales y las pequeñas empresas, España, Ministerio de Trabajo y Seguridad Social. 
Begg, I. (1995). "Threats to Cohesion". Amin y Tomaney (eds), Behind The Myth of European Union. Prospects for cohesion, Routledge, 110-123. (2003). "Complementing EMU: Rethinking Cohesion Policy”. Oxford Review Economic Policy, 19 (1), 161-179.

Boldrin, M. \& Canova, F. (2001). “Europe's Regions, Income Disparities And Regional Policies". Economic Policy, 206-253.

Borgaza, C. \& Maiello, M. (1997). The Contribution of the Social Enterprise to the Creation of New Employment: The Field of Personal Services. University of Trento Consorzio G. Mattarelli, unpublished paper, mimeo.

Brenner, N. (2003a). New State Spaces. Urban Governance and the Rescaling of Stateshood, Oxford University Press.

(2003b). "Metropolitan Institutional Reform Rescaling Of State Space In Contemporary Western Europe", European Urban And Regional Studies, 10 (4), 297-324.

Camagni, R. (ed.) (1991). Innovation Networks: Spatial Perspectives, London: Belhaven-Pinter.

Cameron, D. (1995). “Transnational Relations and The Development of European Economic and Monetary Union”, Risse-Kappen, T. (ed.), Bringing Transnational Relations Back In, Cambridge University Press, 37-76.

Casey, T. (2004). Comparative Disadvantage: Models of Capitalism and Economic Performance in the Global Era, Paper presented at the 2004 Political Studies Association Conference, University of Lincoln, England, April 6-8.

Castells, M. (1996). La sociedad red, Madrid: Alianza Editorial.

Cecchini, P. (1988). "The European Challenge 1992: The Benefits of a Single Market", Aldershot, Wildwood House.

Cheshire, P. \& Magrini, S. (2000). "Endogenous Processes in European Regional Growth: Convergence and Policy", Growth and Change, Vol. 31, 455-479, Blackwell.

Cooke, P. (1998). "Regional Innovate System: an Evolutionary Approach", Cooke; Heidenreich y Braczyk (eds.), Regional Innovation System, $2^{\circ}$ Edition, The Role of Governance in a Globalized World, Routledge, 1-18.

Cooke, P., Morgan, K. (1998). The Associational Economy. Firm, Regions, and Innovation, Oxford University Press.
Coriat, B. (1997). The new dimensions of competitiveness: towards a European approach, IPTS Report, 15.

Crouch, C., Streek, W. (eds.) (1997). Political Economy of Modern Capitalism, London: Sage.

Cuadrado-Roura, J. R. (2001). "Regional Convergence in the European Union: From Hypothesis to the Actual Trends", Ann. Reg. Sci, 35, 333-356.

Cumbers, A. (2000). "The National State As Mediator Of Regional Development Outcomes In A Global Era. A Comparative Analysis From The Uk And Norway", European Urban And Regional Studies, 7(3), 237-252.

Delors Report (1989). Report on Economic and Monetary Union in the European Community, Luxembourg: Office for Official Publications of the European Communities.

Delors, J. (1986). The Single Act and Europe: a Moment of Truth, Florence: European University Institute, 21-37.

Dicken, P., Quévit, M., Savary, J. \& Desterbecq, H. (1994). "Strategies of transnational corporations and European regional restructuring: some conceptual bases", Dicken, P. and Quévit, M. (eds.), Transnational Corporations and European Regional Restructuring, Utrecht: Utrecht University.

Dosi, G. (1997). "The new socio-economics of organization, competitiveness and employment", IPTS Report, 15.

Dunford, M. (1995a). "Cohesion, Growth and Inequality in The European Union”, Amin y Tomaney (eds.), Behind The Myth of European Union. Prospects for cohesion, Routledge, 125-146. (1995b). "Rhone-Alpes: a dynamic region in an age of crisis". Rhodes, Martin (ed.), The regions and the new Europe, Patterns in core and periphery development. Manchester University press.

Dunning, J. (1993). The Theory of Transnational Corporation, London \& New York: Routledge.

Duro, J. A. (2001). Regional Income Inequalities in Europe; an Updated Measurement and Some Decomposition Results, Instituto de Análisis Económico CSIC.

EC - European Commission (1994). Growth, Competitiveness, Employment; The Challenges and Ways Forward into the $21^{1 t}$ Century. White Paper, Luxemburg: Office for Official Publications of the European Communities. 
(1997). The

Competitiveness of European Industry, Luxemburg: Office of Official Publications of the European Communities.

(2001). Unity,

Solidarity, Diversity for Europe, Its People and Its Territory: Second Report on Economic and Social Cohesion, Brussels: Commission of the European Communities.

(2002). Regional clusters in Europe, Observatory of European SMEs 2002, 3 .

(2003a). The

Impact of Member State Policies on Cohesion, Preparatory studies for the Third Cohesion Report.

(2003b). A Study

on the Efficiency of the Implementation Methods for Structural Funds, European Commission Directorate General Regional Policy. (2004). Una

nueva asociación para la cohesión. ConvergenciaCompetitividad-Cooperación. Tercer Informe sobre la cohesión Económica y Social, Luxemburgo: Oficina de Publicaciones Oficiales de las Comunidades Europeas.

ERTI - European Round Table of Industrialist (1993). Beating the Crisis: A Charter for Europe's Industrial Future, Brussels: European Round Table of Industrialists.

ESDP - European Spatial Development Perspective (1999). Towards Balanced and Sustainable Development of The Territory, European Commission.

Esteban, J. M., Grandín, C. \& Ray, D. (1999). Extensions of a measure of polarization, with an application to the income distribution of five $O E C D$ countries, Instituto de Análisis Económico CSIC.

Evans, P. (1995). Embedded Autonomy; States and Industrial Transformation, Princeton University Press.

Fernández, V. R. \& Villalba, M. (2004). "Especialización flexible en América Latina en el marco del Consenso de Washington", Comercio Exterior, 54 (3), 184-195.

Florida, R. (1995). "Toward The Learning Region", Futures, 27 (5), 527-536.

Fujita, M., Krugman, P. \& Venables, A. (1999). The Spatial Economy: Cities, Regions, and
International Trade, Cambridge, MA: MIT Press.

Gill, S. (1998). "European Governance and New Constitutionalism: Economic and Monetary Union and Alternatives to Disciplinary Neoliberalism in Europe", New Political Economy, 3 (1), 5-25.

Henderson, D. (2000). "EU Regional Innovation Strategies Regional Experimentalism In Practice?", European Urban And Regional Studies, 7(4), 347-358.

Hollingsworth, R. (1998). "New Perspective on the Spatial Dimensions of Economic Coordination: Tensions Between Globalization and Social Systems of Production", Review of International Political Economy, 5 (3), 482-507.

Hollingsworth, R. \& Boyer, R. (eds.) (1997). Contemporary Capitalism. The Embeddedness of Institutions, UK: Cambridge University Press.

Hudson, R. (1998a). "Industrial Restructuring in Europe: recent tendencies in the organization and geography of production", Unwin T. (ed.), A European Geography, 169-185, Longman.

(1998b). "The New economy of the New Europe: Eradicting Divisions or Creating New Forms of Uneven Development?", Hudson y Williams (eds.), Divided Europe. Society and Territory, SAGE, 29-62.

(2003). "European Integration And New Forms Of Uneven Development But Not The End OfTerritorially Distinctive Capitalisms In Europe", European Urban and Regional Studies, 10 (1), 49-67.

Hurst, C., Thisse, J. F. \& Vanhoudt, P. (2000). "What Diagnosis For Europe's ailing regions?", EIB Papers, 5 (1), 9-22.

Keating, M. (1998). “The New Regionalism in Western Europe. Territorial Restructuring and Political Change", UK-Nothampton, MA, USA: Edward Elgar Cheltenham.

Krugman, P. (1991). Geography and Trade, Leuven University Press.

(1994). "Competitiviness a Dangerous Obsession”, Foreign Affairs, 73 P, 28-44.

Lake, R. (2002). "Bring Back Big Government", International Journal of Urban and Regional Research, 26 (4), 815-822.

Landabaso, M. (2000). "Las Nuevas Políticas Regionales de Promoción de la Innovación en la 
Unión Europea”, Economía Industrial,335-336/ V-VI, 51-66.

López-Baso, E., Vayá, E., Mora, A. \& Suriñach, J. (1999). "Regional Economic Dynamic and Convergence in The European Union", The Annals of Regional Science, 33, 343-370.

Lundvall, B. (2002). Innovation growth and social cohesion: The Danish model, Hardback.

Maastricht Treaty (1991). Treaty on Economic and Monetary Union, Luxembourg: Office for Official Publications of the European Communities.

Macleod, G. (2001). "New Regionalism Reconsidered: Globalization and the Remaking of Political Economic Space", International Journal of Urban And Regional Research, 25 (4), 804-829.

Malmberg, A. \& Maskell, P. (2002). “The Elusive Concept Of Localization Economies: Towards A Knowledge-Based Theory Of Spatial Clustering", Environment And Planning A 2002, Vol. 34, 429-449.

Mann, M. (1997). "Has Globalization Ended The Rise And Rise OfThe Nation-State?", Review of International Political Economy, 4, 3, Autumn, 472-496.

Markopouliotis, G. (2002). The Policies of the European Union, International. Conference on Geography and Regional Planning in the Enlarged European Union, 17 May, Harokopio University, Athens.

Markusen, A. (1999). "Sticky Places in Slippery Space: A Typology of Industrial Districts", Bryson, J. et al. (eds.), The Economic Geography Reader. Producing and Consuming Global Capitalism, John Wiley y Sons, Ltd, 91-200.

Molle, W., Boeckhout, S. (1995). "Economic Disparity Under Conditions Of Integration - A Long Term View OfThe European Case", Pap. Reg. Sci., 74, 105-123.

Nooteboom, B. (1999). "Innovation and inter-firm linkages: new implications for policy”, Research Policy, 28, 793-805.

Omahe, K. (1996). The End of the Nation State, New York: Free Press.

Overman, H. G. \& Puga, D. (2002). “Unemployment clusters across European regions and countries", Economic Policy, 34 (2), 115-147.

Pearce, J. \& Sutton, J. (1986). Protection and Industrial Policy in Europe, London: Routledge.
Peck, J. \& Tickell, A. (2002). "Neoliberalizing Space", Antipode, 34 (3), 380-404.

Petrella, R. (2000). "The Future of Regions: Why the Competitiveness Imperative Should Not Prevail Over Solidarity, Sustainability and Democracy", Geogr. Ann., 82 B, 2, 67-72.

Porter, M. (2000). "Locations, Clusters, and Company Strategy", Gordon, C. et al. (eds.), The Oxford Handbook of Economic Geography, Oxford University Press, 253-274.

Portes, A. \& Hoffman, K. (2003). "La estructura de clases en América Latina: composición y cambios durante la era neoliberal", Desarrollo Económico, Vol. 43, 171, 355-387.

Puga, D. (2002). "European Regional Policies In Light Of Recent Location Theories", Journal Of Economic Geography, 2, 373-406.

Putnam, R., Leonardi, R. et al. (1993). Making Democracy Work: Civic Traditions In Modern Italy, Princeton, NJ, USA: Princeton University Press.

Quah, D. T. (1996). "Regional Convergence Clusters Across Europe", European Economic Review, 40, 951-958.

Raines, P. (2001). "Local or National Competitive Advantage? The Tensions in Cluster Development Policy", Regional and Industrial Policy Research Paper 43. European Policies Research Centre University of Strathclyde, UK.

Rodríguez-Pose, A. \& Fratesi, U. (2004). "Policy Debates: Between Development And Social Policies: The Impact Of European Structural Funds In Objective 1 Regions", Regional Studies, 38, 1, 97-113.

Rodríguez-Pose, A. \& Petrakos, G. (2004). "Integración económica y desequilibrios territoriales en la Unión Europea", EURE - Revista Latinoamericana de Estudios Urbanos y Regionales, 29, 89, 63-80.

Romer, P. (1994). "The origins of the endogenous growth”, Journal of Economic Perspectives, 8, 1, 3-22.

Rosenberg, J. (2000). The Follies of Globalization Theory, New York: Verso.

Ruggie, J. (1982). Embedded Liberalism in the PostWar Economic Order, International Organization. Sapir, A. (2003). An Agenda for growing Europe. Making the EU Economic System Deliver, Publications Office of the European Union. 
Sassen, S. (2003). "Globalization Or Denationalization?”, Review Of International Political Economy, 10, 1, 1-22.

Scott, A. (1988). New Industrial Spaces, London: Pion.

Scott, A. \& Storper, M. (2003). "Regions, Globalization, Development”, Regional Studies, 37 (6-7), 579-593.

Staeck, N. (1996). "The European Structural Funds- Their History an Impact", Hinelt y Smith (eds.), Policy Networks and European Structural Funds, Avebury, 46-73.

Stiglitz, J. (2003). "El rumbo de las reformas. Hacia una nueva agenda para América Latina”, Revista CEPAL, 80, 7-40.

Storper, M. (1995). “The Resurgence of Regional Economic, Ten Year Later: The Region as a Nexus of Untraded Interdependencies", European Urban and Regional Studies, 2 (3), 191-221.

(1996). "Innovation as Collective Action: Products, Technologies and Territories", Industrial and Corporate Change, 15, 3, 761-790.

Swyngedouw, E. (2000). "Elite Power, Global Forces And The Political Economy of Glocal Development", Clark et al. (eds.), The Oxford Handbook OfEconomic Geography, New York: Oxford University Press, 541-558.

Thisse, J. F. (2000). "Agglomeration And Regional Imbalance: Why? And Is It Bad?”, EIB Papers, 5 (2), 47-67.
Tondl, G. (2001). Convergence after Divergence? Regional Growth in Europe, Berlin: Springer.

Turok, I. (2004). "Cities, Regions And Competitiveness", Regional Studies, 38 (9), 1069-1083.

Van Apeldoorn, B. (1999). Transnational class agency and the Struggle over European Order, Unpublished Ph. D. thesis, European University Institute.

(2003). "The Struggle over European Order: Transnational Class Agency in The Making of Embedded Neo-Liberalism", Benner et al. (eds.), State/Space a Reader, 147 164.

Walker, D. (2002). "In Praise OfCentralism. A Critique Of The New Localism”, A Catalyst Working Paper 4, London: Catalyst.

Weiss, L. (1998). The Myth of the Powerless State, Ithaca, NY: Cornell University Press.

Williams, A. (1998). "The European Union: cumulative and uneven integration", Unwin, T. (ed.), A European Geography, Longman, 129147.

Young, B. (2000). “Disciplinary Neoliberalism In The European Union And Gender Politics", New Political Economy, 5 (1), 77-98.

Zysman, J. \& Schwartz, A. (1998). "Reunifying Europe in an Emerging World Economy: Economic Heterogeneity, New Industrial Options, and Political Choices", Journal of Common Market Studies, Vol. 6, 3, 405-429. 